\title{
Intertemporal hedge for inflation risk
}

\author{
JOW-RAN CHANG and MAO-WEI HUNG* \\ Department of International Business, College of Management, National Taiwan \\ University, No. 1, Section 4, Roosevelt Road, Taipei, Taiwan
}

An asset pricing model is developed in which price of consumption good is unknown and investors have a general time and state nonseparable preference. It is shown that the expected return on an asset is determined by a weighted average of market risk, inflation risk and consumption risk. The sum of these weights is equal to one. Moreover, a log-linear approximation proposed by Campbell (1993) to budget constraint is used to substitute out consumption to obtain an asset pricing model with inflation hedging risk. In this setup, expected asset return can be rewritten as a weighted average of market risk, market hedging risk, inflation risk and inflation hedging risk.

\section{INTRODUCTION}

The relationship between expected asset return and inflation risk has been widely documented. For example, Marshall (1992) documents that real stock returns are negatively correlated with inflation, expected or unexpected. Moreover, stock price levels are negatively correlated with the price level with consumption. In a recent paper, Bakshi and Chen (1996) study endogenous determination of the price level, inflation and asset price. But, investors in these models are assumed to maximize a time-additive, von Neumann-Morgenstern expected utility of the life-time consumption function. This implies that two distinct concepts of intertemporal substitution and risk aversion are characterized by the same parameter. In addition, the difficulty of a consumption-based asset pricing model may occur when using aggregate consumption data, which are measured with error and are time-aggregated. To avoid this difficulty, Campbell (1993) develops an asset pricing model that does not rely on direct measurements of consumption. He demonstrates that the conditional covariance of any asset return with consumption growth can be rewritten in terms of conditional covariances with the return on the market and revisions in expectations of future returns on the market.
The main goal of this paper is to separate intertemporal inflation hedging risk from inflation risk. This is accomplished by extending Campbell's model to a random inflation framework in which investor's utility depends on real returns rather than nominal returns. Compared to the nonrandom inflation model, in addition to market risk and market hedging risk, inflation risk and inflation hedging risk are priced in the model. While the market hedging risk is the covariance of asset returns with news about the discounted value of all future world market returns, the inflation hedging risk is the covariance of asset return with news about the discounted value of all future inflation returns.

This study contains several contributions. First, a recursive preference is employed which separates investor's attitudes towards risk from willingness to substitute future consumption for present consumption in pricing international assets. In this setup, it is shown that expected asset return can be expressed as a weighted average of consumption risk, inflation risk and market risk. Second, a log-linear approximation to the budget constraint is used to substitute out consumption from a standard asset pricing model to obtain an asset pricing model with inflation hedging risk in a random inflation setting. In this approach, it is shown that expected asset return is deter-

* Corresponding author. E-mail: hung@handel.mba.ntu.edu.tw 
mined by a weighted average of market risk, market hedging risk, inflation risk and inflation hedging risk. Moreover, these weights are summed up to one.

The remainder of the paper is organized as follows. Section II derives the model of random inflation asset pricing in which investors are endowed with recursive preferences. Section III uses the log-linear budget constraint to derive an asset pricing model with inflation hedging risk in random inflation framework. Finally, Section IV concludes the paper.

\section{PORTFOLIO CHOICE}

In this section, the problem of optimal consumption and portfolio allocation in a unified capital market with no taxes or transactions costs is considered. Investors are assumed to maximize a Kreps-Porteus utility of their lifetime consumption function.

$C_{t}$ is defined as the current nominal consumption level at time $t$ and $P_{t}$ is the price level index at time $t$. In the setup of the Kreps and Porteus (1978) nonexpected utility, the aggregator function is parameterized to be homogenous of degree one in current real consumption and in the value of future state-dependent real consumption:

$$
U\left[\frac{C_{t}}{P_{t}}, \underset{t}{E} V_{t+1}\right]=\left[(1-\delta)\left(\frac{C_{t}}{P_{t}}\right)^{1-\rho}+\delta\left(\underset{t}{E} V_{t+1}\right)^{\frac{1-\rho}{1-\lambda}}\right]^{\frac{1-\lambda}{1-\rho}}
$$

where $\lambda$ is the Arrow-Pratt coefficient of relative risk aversion, $\rho$ can be interpreted as the elasticity of intertemporal substitution, and $\delta \in(0,1)$ is the subjective discount factor.

The representative agent's dynamic budget constraint in terms of real variables can be written as:

$$
\frac{W_{t+1}}{P_{t+1}}=R_{m, t+1} \frac{P_{t}}{P_{t+1}}\left(\frac{W_{t}}{P_{t}}-\frac{C_{t}}{P_{t}}\right)
$$

where $W_{t+1}$ is the investor's nominal wealth at time $t$. The budget constraint in Equation 2 is nonlinear because of the interaction between subtraction and multiplication. It is straightforward to show that the Euler equations can be derived as:

$$
\begin{gathered}
\underset{t}{E}\left\{\left[\delta\left(\frac{C_{t+1} / P_{t+1}}{C_{t} / P_{t}}\right)^{-\rho}\right]^{\theta}\left(R_{m, t+1} \frac{P_{t}}{P_{t+1}}\right)^{\theta-1} R_{i, t+1} \frac{P_{t}}{P_{t+1}}\right\}=1 \\
i=1, \ldots, N
\end{gathered}
$$

where $\theta=(1-\lambda) /(1-\rho)$. These are the real form of Euler equations which are similar to the nominal form of Euler equations in Epstein and Zin (1989).

Assume that asset prices and consumption are jointly lognormal or use a second order Taylor expansion to the Euler equation when it is assumed that asset prices and consumption are conditional homoscedastic. Then, the log-version of the real Euler Equation 3 can be represented as:

$$
\begin{aligned}
0= & \theta \log \delta-\theta \rho \underset{t}{E} \Delta c_{t+1}+(\theta-1) \underset{t}{E} r_{m, t+1}+\underset{t}{E} r_{i, t+1} \\
& +\theta(\rho-1) \underset{t}{E} \Delta \pi_{t+1}=\frac{1}{2}\left[(\theta \rho)^{2} V_{c c}+(\theta-1)^{2} V_{m m}\right. \\
& \left.+V_{i i}-2 \theta \rho(\theta-1) V_{c m}-2 \theta \rho V_{c i}+2(\theta-1) V_{i m}\right] \\
& +\frac{1}{2}\left\{\left[(\theta(\rho-1)]^{2} V_{\pi \pi}+2 \theta^{2} \rho(\rho-1) V_{\pi c}\right.\right. \\
& \left.+2 \theta(\theta-1)(\rho-1) V_{\pi m} 2 \theta(\rho-1) V_{\pi i}\right]
\end{aligned}
$$

where $V_{c c}$ denotes $\operatorname{Var}_{t}\left(c_{t+1}\right), \quad V_{j j}$ denotes $\operatorname{Var}_{l}\left(r_{j, t+1}\right) \forall j=i, m, V_{c j}$ denotes $\operatorname{Cov}_{t}\left(c_{t+1}, r_{j, t+1}\right) \forall j=i, m$, $V_{i m}$ denotes $\operatorname{Cov}_{t}\left(r_{i, t+1}, r_{m, t+1}\right), V_{i \pi}=\operatorname{Cov}_{t}\left(r_{i, t+1}, \pi_{t+1}\right)$, and $\pi_{t+1}=\mathrm{d} \ln \left(P_{t+1}\right)=\left(\mathrm{d} P_{t+1} / P_{t+1}\right)$.

When we subtract the risk free version of (4) is subtracted from the general version:

$$
\underset{t}{E} r_{i, t+1}-r_{f, t+1}=-\frac{V_{i i}}{2}+\theta \rho V_{i c}+(\theta-\theta \rho) V_{i \pi}+(1-\theta) V_{i m}
$$

is obtained where $r_{f, t+1}$ is a log riskless real interest rate. This result is similar to Campbell (1993) except for the inflation term. Equation 5 shows that the expected excess $\log$ return on an asset is a linear combination of its own variance, which is produced by Jensen's inequality, and by a weighted average of three covariances. The weights on the consumption, inflation and market are $\theta \rho,(\theta-\theta \rho)$ and $(1-\theta)$, respectively. Moreover, the weights are summed up to 1 . This is one of the most important differences between Campbell's model and the present model.

\section{INFLATION HEDGING RISK}

In order to substitute out consumption and get a pricing formula with inflation hedging risk, the technique of Campbell (1993) is applied. Campbell (1993) suggests to linearize the budget constraint by dividing the nominal form of Equation 2 by $W_{t}$, taking the log, and then using a first-order Taylor approximation around the mean log consumption/wealth ratio $\log (C / W)$. Following his approach, the conditional covariance of any asset return with consumption can be rewritten in terms of covariance with the return on the market and revisions in expectations of future return on the market:

$$
\begin{aligned}
\operatorname{cov}_{t}\left(r_{i, t+1}, \Delta c_{t+1}\right) \equiv & V_{i c}=V_{i m}+\left(1-\frac{1}{\rho}\right) V_{i h} \\
& -\left(1-\frac{1}{\rho}\right) V_{i h \pi}
\end{aligned}
$$




$$
v_{i h}=\operatorname{Cov}_{t}\left(r_{i, t+1},(\underset{t+1}{E}-\underset{t}{E}) \sum_{j=1}^{\infty} \rho^{j} r_{m, t+1+j}\right)
$$

and

$$
V_{i h \pi}=\operatorname{Cov}_{t}\left(r_{i, t+1},(\underset{t+1}{E}-\underset{t}{E}) \sum_{j=1}^{\infty} \rho^{j} \pi_{t+1+j}\right)
$$

Substituting Equation 6 into Equation 5, gives an asset pricing model, which is not related to consumption and contains an inflation hedging risk:

$$
\begin{aligned}
\underset{t}{E} r_{i, t+1}-r_{f, t+1}= & -\frac{V_{i i}}{2}+\lambda V_{i m}+(\lambda-1) V_{i h}+(1-\lambda) V_{i \pi} \\
& +(1-\lambda) V_{i h \pi}
\end{aligned}
$$

The only preference parameter that enters Equation 7 is the coefficient of relative risk aversion $\lambda$. The elasticity of intertemporal substitution $\rho$ has disappeared in this pricing model. Equation 7 states that the expected excess log return of an asset, adjusted for Jensen's inequality effect, is a weighted average of four covariances. These are the covariance with the return from the market portfolio, the covariance with news about future returns on invested wealth, the covariance with the return from inflation, and the covariance with news about future inflation. These results differ from those documented in Campbell (1993). Since Campbell's intertemporal model is a nonrandom inflation model, it does not deal with the issues of inflation that are emphasized in the asset pricing model with random inflation. Therefore, neither $V_{i \pi}$ or $V_{i h \pi}$ appears in his pricing formula.

\section{CONCLUSION}

This paper develops an asset pricing model in which inflation is random in each time period and investors have a general time and state nonseparable preference. In order to overcome the measurement error problem of aggregate consumption, the technique of log-linearing the budget constraint proposed by Campbell (1993) to obtain an asset pricing model with inflation hedging risk is explored.

Some interesting results are obtained which have not been documented in previous studies. First, the pricing formula shows that expected asset return can be expressed as a weighted average of three covariances: market risk, consumption risk, and inflation risk. The weights of these three covariances are summed up to one. Second, the random inflation asset pricing model with inflation hedging risk proposes that the expected asset return is determined by market risk, market hedging risk, inflation risk, and inflation hedging risk. The weights are related only to the coefficient of relative risk aversion. Moreover, the weights are summed up to one. This model extends the results documented in Adler and Dumas (1983), who assume a constant investment opportunity set, and hence their model is not capable of explaining market hedging risk and inflation hedging risk.

\section{REFERENCES}

Bakshi G. S. and Chen, Z. (1996) Inflation, asset prices, and the term structure of interest rates in monetary economies, The Review of Financial Studies, 9, 241-75.

Campbell, J. Y. (1993) Intertemporal asset pricing without consumption data, American Economic Review, 83, 487-512.

Epstein, L. G. and Zin, S. E. (1989) Substitution, risk aversion, and the temporal behavior of consumption and asset returns: a theoretical framework, Econometrica, 57, 937-69.

Kreps, D. and Porteus, E. (1978) Temporal resolution of uncertainty and dynamic choice theory, Econometrica, 46, 185200.

Marshall, D. (1992) Inflation and asset return in a monetary economy, Journal of Finance, 47, 1315-42. 